\title{
Influence of Low-temperature Oxidation on Structure of Coke Making Coal
}

\author{
Munehiro UCHIDA, ${ }^{1) *}$ Koji KANEHASHI, ${ }^{2)}$ Kazuya UEBO,${ }^{1)}$ Seiji NOMURA, ${ }^{1)}$ Koji SAITO, ${ }^{3)}$ Yuuji FUJIOKA, ${ }^{4)}$ \\ Jun-ichi OZAKI' ${ }^{5)}$ and Takayuki TAKARADA ${ }^{6)}$
}

1) Process Research Laboratories, Nippon Steel \& Sumitomo Metal Corporation, 20-1 Shintomi, Futtsu, Chiba, $293-8511$ Japan. 2) Advanced Technology Research Laboratories, Nippon Steel \& Sumitomo Metal Corporation, 20-1 Shintomi, Futtsu, Chiba, 293-8511 Japan.

3) Technical Research \& Development Bureau, Nippon Steel \& Sumitomo Metal Corporation, 20-1 Shintomi, Futtsu, Chiba, 293-8511 Japan.

4) Futtsu Unit Nippon Steel \& Sumikin, Technology Corporation, 20-1 Shintomi, Futtsu, Chiba, $293-0011$ Japan.

5) International Research and Education Center for Element Science, Gunma University, 1-5-1 Tenjin-cho, Kiryu, Gunma, 3768515 Japan.

6) Division of Environmental Engineering Science, Graduate School of Science and Technology Gunma University, 1-5-1 Tenjin-cho, Kiryu, Gunma, 376-8515 Japan.

(Received on April 26, 2019; accepted on May 16, 2019; originally published in Tetsu-to-Hagané, Vol. 104, 2018, No. 8, pp. 461-468)

\begin{abstract}
Self-exothermic reaction of coal is initiated by the reaction of coal in a pile with oxygen in the air to be oxidized. Then, the heat generated by the oxidation promotes further oxidation, resulting in ignition. In order to prevent this phenomenon, it is necessary to understand the initial stage of oxidation of coal in the condition of heat-accumulation. Conventionally, there are very few researches to understand the early stage of coal oxidation. In this study, we aimed at to elucidate the earlier oxidation stage of coals by employing low temperature oxidation of a mass of coals and several instrumental analysis techniques. The oxidation we used were heating $50 \mathrm{~g}$ of coal charged in a stainless steel closed container at $80^{\circ} \mathrm{C}$ for 24 $\mathrm{h}$ by flowing hot air to simulate the self-exothermic reaction condition. XRD and Raman spectroscopic measurements showed that the carbon skeleton structure of coal did not change by the oxidation treatment, while FTIR, ${ }^{1} \mathrm{H}$ NMR and ${ }^{13} \mathrm{C}$ NMR measurements showed a decrease in aliphatic side chains and an increase in hydroxyl groups in coal. The information obtained here will help to understand the whole process of self-exothermic reaction of coal to prevent burning.
\end{abstract}

KEY WORDS: coal; oxidation; structural change.

\section{Introduction}

The environment of coke production has recently been undergoing substantial changes due to the coal price ${ }^{1)}$ and resource quality degradation. In such a situation, it is essential to ensure a stable supply of heavy coking coal, the main raw material for producing high-strength coke. However, the proportion of this kind of coal is less than $10 \%$ of all known coal deposits. To expand resource availability, technical development has been advancing to make it possible to use non- or slightly caking coal, which is inferior to caking coal in terms of its caking property. Specifically, an appropriate combination $^{6)}$ of coal crushing, ${ }^{2,3)}$ coal moisture control ${ }^{4,5)}$ (a classification process), and other technologies has made it possible to produce high-strength coke of stable quality from blended coal partially containing non- or slightly caking coal.

Coal generally exhibits exothermic reaction, a phenomenon whereby coal gradually oxidizes by absorbing atmo-

\footnotetext{
* Corresponding author: E-mail: uchida.g3g.munehiro@jp.nipponsteel.com DOI: https://doi.org/10.2355/isijinternational.ISIJINT-2018-808
}

spheric oxygen and finally generates heat. ${ }^{10)}$ In particular, it is known that coal with a higher oxygen content tends to generate more heat. ${ }^{11)}$ Because non- or slightly caking coal contain a higher oxygen content than heavy coking coal, they are accordingly expected to easily oxidize to generate heat. To expand the use of non- or slightly caking coal, it is necessary to manage the safety of blended coal.

Coal-mining countries recognize operational risks ${ }^{12,13)}$ caused by the self-heating of coal in coal mining, and there have been a number of studies undertaken on this problem. Examples include studies on the oxidation process that have analyzed mass change, ${ }^{14,15)}$ changes in thermophysical properties $^{16,17)}$ and gas products, ${ }^{18)}$ with the aid of TG-DTA and other equipment. Since coal oxidation progresses from coal particle surfaces, ${ }^{19)}$ infrared spectroscopy (IR $)^{20,21)}$ and X-ray photoelectron spectroscopy (XPS ${ }^{22)}$ have been performed to analyze the production process of compounds produced by oxidation. To identify structural changes occurring in bulk coal, structural analysis of coal has also been performed by applying the nuclear magnetic resonance method (NMR) ${ }^{23)}$ or the like. Other studies using isotopic oxygen ${ }^{24,25)}$ have 
investigated in detail the behavior of oxygen in the oxidation process. However, most of those studies deal with coal that has been fully oxidized. For example, Clemens et al. performed a coal oxidation test at 30 to $180^{\circ} \mathrm{C}$ for 5 to 130 hours, ${ }^{26)}$ and Guangheng et al. conducted a coal oxidation test at $125^{\circ} \mathrm{C}$ for as long as 14 days; ${ }^{27)}$ in those tests, they analyzed changes in functional groups by IR. As was the case with those tests, the oxidation dealt with in many studies is a process that occurs in a hot state $\left(100^{\circ} \mathrm{C}\right.$ or higher $)$ or a process in a cold state at a temperature of $100^{\circ} \mathrm{C}$ or lower for a long period that ranges from several days to several months. Those tests were performed by using only small amounts of samples; Clemens et al. performed their oxidation test by using a small sample of $1.5 \mathrm{~g}$, and Guangheng et al. conducted their oxidation test on a $50 \mathrm{~g}$ sample but with the sample spread out on a pallet $(250 \mathrm{~mm} \times 200$ $\mathrm{mm})$. Most of the past tests were performed using small amounts of sample or under a thin-stratified condition. In oxidation tests performed using a small amount of sample or under a thin-stratified condition, however, the amount of heat released to the atmosphere becomes large; accordingly, it is difficult to simulate the oxidation process that occurs in a stratified state inside a coal bin. It has been reported that even under the same temperature conditions, the self-heating of coal exhibits substantial differences in heat-generating behavior, such as the rate of temperature rise, depending on whether a stratified state is present. ${ }^{28)}$ In actual industrial applications, coal is stored in a stratified state; this means to analyze the heat-generation characteristic of coal, it is essential to perform a test in a stratified state (packed bed) in which heat of reaction generated by the oxidation process is not easily released to the atmosphere.

It has also been reported that coal oxidation progresses slowly at low temperatures. ${ }^{29,30}$ To sufficiently grasp the mechanism of self-heating, it is important to analyze the fine structural changes that occur in coal in the initial stage at low temperatures. In this report, therefore, we used samples prepared by subjecting blended coal for coke production to the oxidation process in a packed-layer state at low and high temperatures, and analyzed their structural changes with the aid of various instrumental analyses, namely X-ray diffractometry (XRD), laser Raman spectroscopy, FTIR, and solid-state NMR.

\section{Experimental}

\subsection{Preparation of Samples}

For this experiment, we prepared two types of samples (low-temperature oxidation and high-temperature oxidation samples) according to the following procedure. The hightemperature oxidation sample was prepared as a comparison sample for grasping extreme structural changes that will occur if the low-temperature oxidation sample undergoes thermal hysteresis through continuous oxidation.

We prepared the low-temperature oxidation sample in the following manner: $50 \mathrm{~g}$ of blended coal (average particle size: $3 \mathrm{~mm}$ ) was packed with air into an SUS container (50 $\mathrm{mm}$ in diameter $\times 50 \mathrm{~mm}$ in height) in a stratified state, and the container with the packed coal was left standing for 24 hours within a thermostatic chamber that blows atmospheric air at $80^{\circ} \mathrm{C}$. The packing density of the coal was approxi- mately $0.8 \mathrm{~g} / \mathrm{cm}^{3}$, and the sample yield was almost $100 \%$. We left the top of the container open to allow natural convection in the system, supplying oxygen to the packed coal bed mainly through the surface layer. Approximately $40 \mathrm{~g}$ of the prepared sample was used as samples for industrial and elemental analyses, and the remainder was used as samples for other instrumental analyses.

The high-temperature oxidation sample was prepared by using the same blended coal as raw material and packing it into a cylindrical SUS container (pail with the following dimensions: $300 \mathrm{~mm}$ in diameter $\times 200 \mathrm{~mm}$ in height) with no cover. We placed an insulating material (product of ShinNippon Thermal Ceramics Corporation, with the following dimensions: $300 \mathrm{~mm}$ in diameter $\times 50 \mathrm{~mm}$ in height) inside the container at the bottom, and on the insulating material, packed an approximately 5-kg sample of pulverized coal (average particle size: $3 \mathrm{~mm}$ ) into the container up to depth of $100 \mathrm{~mm}$. After that, we inserted a thermocouple into the center area to a depth of $60 \mathrm{~mm}$ from the surface and measured the temperature in the packed coal bed. The pail packed with sample coal was left standing in the air-blowing thermostatic chamber; however, to prevent the sample coal from oxidizing as the temperature rose from room temperature to the test-starting temperature $\left(80^{\circ} \mathrm{C}\right)$, we replaced the air in the system with nitrogen gas. When the temperature inside the packed coal bed reached $80^{\circ} \mathrm{C}$, we switched the atmosphere in the air-blowing thermostatic chamber from nitrogen to atmospheric air (moisture content: atmospheric humidity); the point of this switching was regarded as the start of the test. After the switching to air, the system was a state of natural convection, and oxygen was supplied to the packed coal bed mainly through the surface layer. We analyzed the waste gas discharged from the top of the airblowing thermostatic chamber after the start of the test with a Horiba, Ltd. PG-330 portable gas analyzer. When the temperature of the inside of the packed coal bed reached $300^{\circ} \mathrm{C}$ or higher, we water-cooled the cylindrical container to room temperature and used the sample coal as the hightemperature oxidation sample. Inferring from the values described later measured using proximate analysis, we think the sample yield was more than $80 \%$.

\subsection{Analytical Methods}

\subsubsection{XRD}

The XRD pattern was captured with an X-ray diffractometer (Ultima III from Rigaku Corporation), using $\mathrm{Cu}-\mathrm{K}_{\alpha}$ $(0.154056 \mathrm{~nm})$ as the X-ray source, and the pattern was analyzed using the carbon material-analysis software, Carbon Analyzer FE2011. Since we expected the structural changes of the low-temperature oxidation sample from the blended coal to be small, the measurement was performed by adding an internal standard substance (Si) in order to analyze the differences in detail.

\subsubsection{Raman Spectroscopy}

We performed Raman spectrum measurement with a Model NRS-7100 (JASCO Corporation), using a laser beam with a wavelength of $532 \mathrm{~nm}$ as excitation source. Measured spectra were subjected to baseline correction in the range of 960 to $2000 \mathrm{~cm}^{-1}$. After that, we conducted spectral fitting assuming five components G, D1, D2, D3, and D4 ${ }^{31)}$ in such 
a way as to minimize the differences between measured values and a spectrum synthesized from the individual component waves.

\subsubsection{FTIR}

The IR spectrum was measured using a Model FT/ IR-6100 (JASCO Corporation). Samples were prepared according to the $\mathrm{KBr}$ tablet method, and 80 integrations were measured at a resolution of $4 \mathrm{~cm}^{-1}$.

\subsubsection{Solid ${ }^{13} \mathrm{C}$ NMR and Solid ${ }^{1} \mathrm{H}$ NMR}

We conducted solid ${ }^{13} \mathrm{C}$ NMR measurement and solid ${ }^{1} \mathrm{H}$ NMR spectrum measurement under a magnetostatic field intensity of $11.7 \mathrm{~T}$ with an INOVA-500 spectrometer (Agilent Technologies Japan, Ltd.). The resonance frequencies of ${ }^{13} \mathrm{C}$ and ${ }^{1} \mathrm{H}$ were $125.69 \mathrm{MHz}$ and 499.86 MHz, respectively, and the sample spinning speed was set to $20 \mathrm{kHz}$ for ${ }^{13} \mathrm{C}$ and to 58 $\mathrm{kHz}$ for ${ }^{1} \mathrm{H}$. The number of light integrations was set as 900 to 2400 for solid ${ }^{13} \mathrm{C}$ NMR spectrum measurement and to 128 for solid ${ }^{1} \mathrm{H}$ NMR spectrum measurement. For the solid ${ }^{13} \mathrm{C}$ NMR, we employed the spin echo method for its pulse sequence, whereas for solid ${ }^{1} \mathrm{H}$ NMR, we applied a combination of the single-pulse method with the DEPTH method ${ }^{32)}$ in order to cancel background noise from the probe.

\section{Results and Discussions}

\subsection{Temperature Changes Inside the Packed Coal Bed}

Figure 1 shows changes in the temperature inside the packed coal bed in the coal oxidation test that used the pail. The temperature inside the packed coal bed slowly rose to $85^{\circ} \mathrm{C}$ in 1 day from the start of the test, and after that, it exhibited a rapid rise. This fact indicates that the

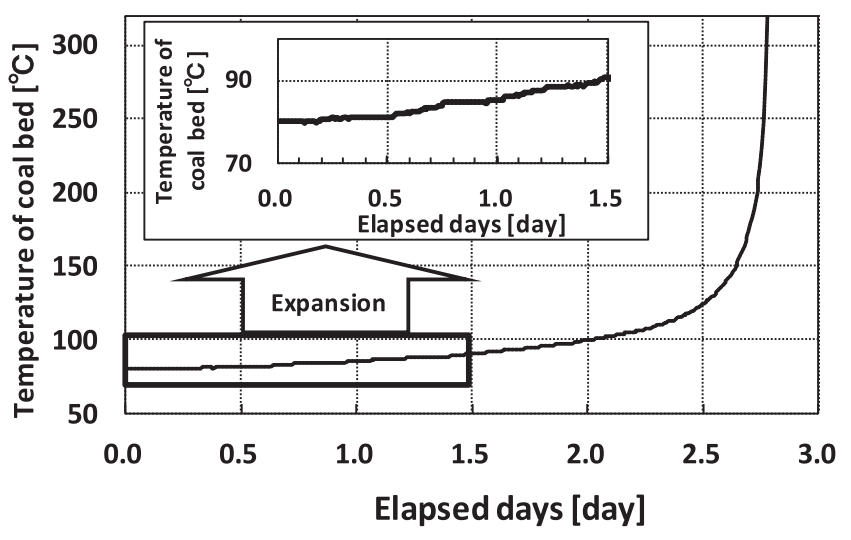

Fig. 1. Trend in temperature of coal bed. oxidation process progressed in coal even at an atmospheric temperature as low as $80^{\circ} \mathrm{C}$, and that at least 1 day later, the temperature inside the packed bed started to rise. This fact suggests that oxidation progresses under the abovementioned conditions.

\subsection{Results of Proximate and Ultimate Analyses}

Table 1 shows the results of the proximate and ultimate analyses. No distinctive differences were detected between the blended coal and the low-temperature oxidation sample in the results of the proximate and ultimate analyses. On the other hand, the high-temperature oxidation coal exhibited substantial changes in the values measured in the proximate and ultimate analyses. The volatile content decreased from 25.9 mass \% (dry) for the blended coal to 8.1 mass \% (dry). According to the ultimate analysis results, carbon increased from 87.4 mass \% (d.a.f.) to 89.4 mass \% (d.a.f.), and hydrogen decreased from 4.9 mass $\%$ (d.a.f.) to 1.9 mass $\%$ (d.a.f.). These changes observed in the high-temperature oxidation sample were brought about by the hysteresis that the sample underwent at temperatures of $300^{\circ} \mathrm{C}$ or higher.

\subsection{X-ray Diffraction (XRD) Measurement Results}

It is generally known that coal changes its crystal structure when heated. ${ }^{33,34)}$ To examine changes in the crystallite size of the two samples, we performed XRD measurement. Figure 2 shows the XRD profiles of the blended coal, the low-temperature oxidation sample, and the high-temperature oxidation sample. In the XRD profiles of the blended coal (base) and the low-temperature oxidation sample, some peaks are found at $2 \theta=28^{\circ}$ and in the high-angle region. Those peaks are caused by the presence of $\mathrm{Si}$ as the internal standard.

No distinctive differences were detected between the XRD pattern of the blended coal and that of the low-temperature oxidation sample. On the other hand, the high-temperature oxidation sample exhibited the following: a peak in the range of $2 \theta=10$ to $33^{\circ}$ became sharper; the peaks at $2 \theta=$ 12,20 , and $25^{\circ}$ brought about by kaolin decreased; and the peak intensity of $\mathrm{CaCO}_{3}$ at $2 \theta=29^{\circ}$ decreased slightly. These observed facts suggest that the dehydration of kaolin and the decarboxylation of $\mathrm{CaCO}_{3}$ occurred due to heating to a temperature of $300^{\circ} \mathrm{C}$ or higher. It is known that the dehydration and decarboxylation of inorganic matter occur at temperatures as high as $500^{\circ} \mathrm{C},{ }^{35)}$ and the results obtained by XRD in this study are consistent with such knowledge.

Table 2 lists the crystallite sizes obtained from the individual samples by the XRD pattern analysis. ${ }^{36-38)}$ The crystallite size of the low-temperature oxidation sample

Table 1. Chemical compositions of coal samples.

\begin{tabular}{|c|c|c|c|c|c|c|c|c|}
\hline & \multirow{2}{*}{$\begin{array}{c}\begin{array}{c}\text { Proximate } \\
\text { analysis }\end{array} \\
\text { VM }\end{array}$} & \multicolumn{5}{|c|}{ Ultimate analysis } & \multirow[t]{3}{*}{$\mathrm{H} / \mathrm{C}$} & \multirow[t]{3}{*}{$\mathrm{O} / \mathrm{C}$} \\
\hline & & $\mathrm{C}$ & $\mathrm{H}$ & $\mathrm{N}$ & $\mathrm{O}$ & $\mathrm{S}$ & & \\
\hline & mass $\%$, dry & d.a.f $\%$ & d.a.f $\%$ & d.a.f $\%$ & d.a.f $\%$ & d.a.f $\%$ & & \\
\hline $\begin{array}{l}\text { Raw coal (Blended coal for } \\
\text { cokemaking: bace sample) }\end{array}$ & 26.9 & 87.4 & 4.9 & 1.7 & 6.4 & 0.5 & 0.672 & 0.055 \\
\hline Low temperature oxidized coal & 26.9 & 87.3 & 5.0 & 1.7 & 6.5 & 0.5 & 0.678 & 0.056 \\
\hline High temperature oxidized coal & 8.1 & 89.4 & 1.9 & 1.9 & 6.3 & 0.6 & 0.253 & 0.053 \\
\hline
\end{tabular}



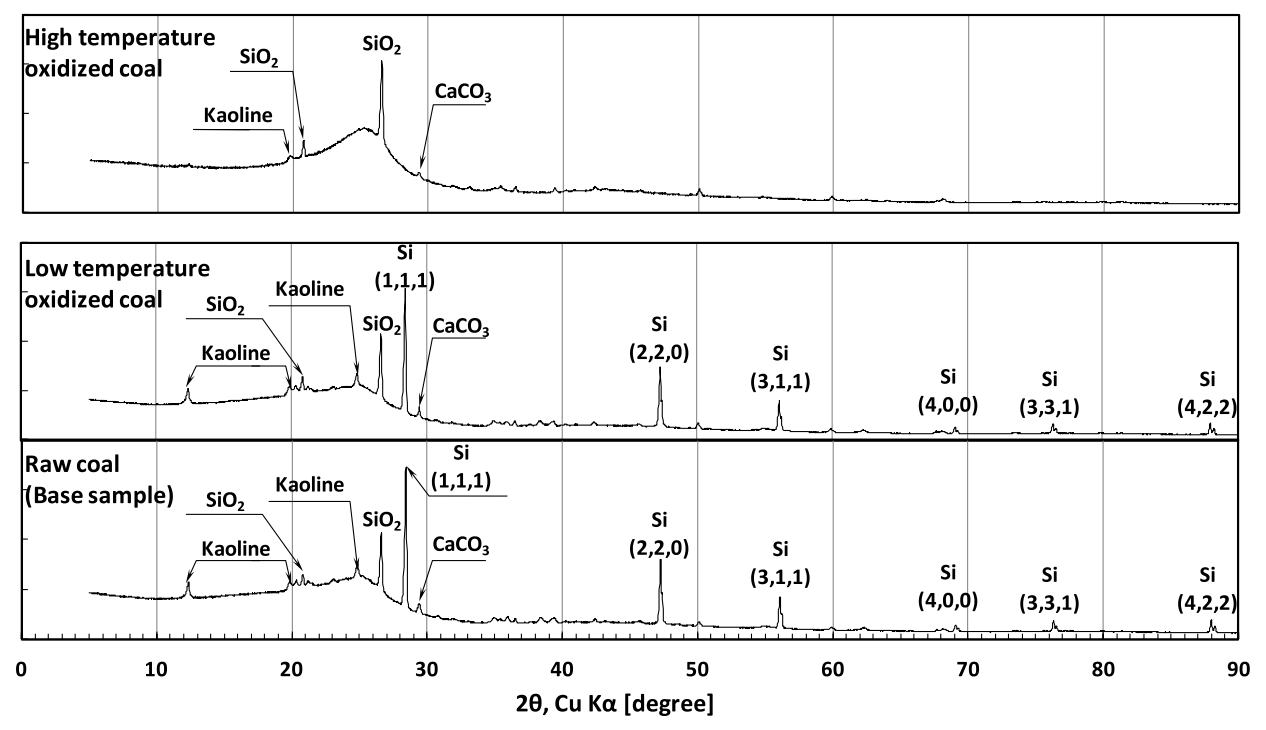

Fig. 2. XRD patterns of coal samples.

Table 2. Crystallite size of coal samples.

\begin{tabular}{cc}
\hline & Crystallite size Lc [nm] \\
\hline Raw coal (base sample) & 1.2 \\
Low temperature oxidized sample & 1.2 \\
High temperature oxidized sample & 1.6 \\
\hline
\end{tabular}

was $1.2 \mathrm{~nm}$, which is the same as that of the blended coal. However, the crystallite size of the high-temperature oxidation sample was $1.6 \mathrm{~nm}$, which was larger than those of the other samples. This fact suggests that the carbon structure grew in the high-temperature oxidation process.

As described above, there was no observed sign in the XRD measurements that the carbon skeleton structure of coal changes in the oxidation process at a temperature as low as $80^{\circ} \mathrm{C}$. On the other hand, structural change of inorganic matter contained in coal and an increase in the carbon crystallite size were seen in the high-temperature oxidation sample. We think these changes came about by the hysteresis that coal underwent during the high-temperature process at temperatures of $300^{\circ} \mathrm{C}$ or higher.

\subsection{Raman Spectroscopy Measurement Results}

We performed Raman spectroscopy measurement ${ }^{39)}$ to analyze disturbance to the carbon structure and the crystallinity of each sample. Figure 3 shows the Raman spectra and the results from analyzing them. The measurement was performed by radiating three different points of each sample with a laser beam (spot diameter: $0.7 \mu \mathrm{m}$ ), and the figure contains the spectra corresponding to the three different points. The average of the intensity ratio (hereinafter referred to as the $\mathrm{R}$ value $)^{40,41)}$ between the $\mathrm{G}$ band near $1580 \mathrm{~cm}^{-1}$ and D band near $1360 \mathrm{~cm}^{-1}$ obtained by waveform separation and the half-value width $\left(\Delta \mathrm{G}_{\mathrm{H} / 2}\right)$ of the $\mathrm{G}$ band were calculated and also appear in the figure.

As Fig. 3 shows, there are no substantial differences in spectral form among the samples when variations due to the measurement points are taken into consideration. For the $\mathrm{R}$ value, which is regarded as an index representing disturbance to the carbon structure, all the samples took the same value. For $\Delta \mathrm{G}_{\mathrm{H} / 2}$, which is regarded as an index for representing the homogeneity of the crystal structure, there was no difference between the blended coal and the low-temperature oxidation sample, and the high-temperature oxidation sample exhibited a small value.

Thus, the Raman spectroscopy results suggest that the low-temperature oxidation sample has a carbon structure equivalent to that of the blended coal, and that the carbon skeleton structure grows more in the high-temperature oxidation sample.

\subsection{Measurement Results of Solid ${ }^{13} \mathrm{C}$ NMR}

As the next step, solid ${ }^{13} \mathrm{C}$ NMR measurement was performed in order to examine the changes in the carbon structure that occur with changes in temperature.

Figure 4 shows the spectrum of each sample. The observed peaks were roughly divided into the two that have peak tops around $130 \mathrm{ppm}$ and $30 \mathrm{ppm}$; the two are a peak brought about by aromatic carbon and that brought about by aliphatic carbon, respectively. ${ }^{42)}$ For all the samples, the peak brought about by the aromatic carbon is similar in shape.

In the spectra of both the blended coal and the lowtemperature oxidation sample, the peaks brought about by aromatic carbon were very similar in shape. In the peak brought about by aliphatic carbon, however, there was some difference between the two samples, and the peak intensity of the low-temperature oxidation sample slightly decreased. The spectral intensity indicates that the abundance ratio of methylene groups and that of methine groups decreased by approximately $3 \%$. In those spectra, the fa value increased from 0.75 for the blended coal to 0.78 for the low-temperature oxidation sample. It has been reported that in coal with a high oxygen content, the number of aliphatic side chains generally decreases at a temperature of $100^{\circ} \mathrm{C}$ and above. ${ }^{43)}$ Accordingly, it is difficult to imagine that at a temperature as low as $80^{\circ} \mathrm{C}$, the thermal decomposition reaction of aliphatic side chains occurs at level sufficient to allow the fa value to change. Therefore, the increase in the fa value in low-temperature oxidation at $80^{\circ} \mathrm{C}$ suggests that this sample underwent thermal hysteresis due to a temperature of $100^{\circ} \mathrm{C}$ 

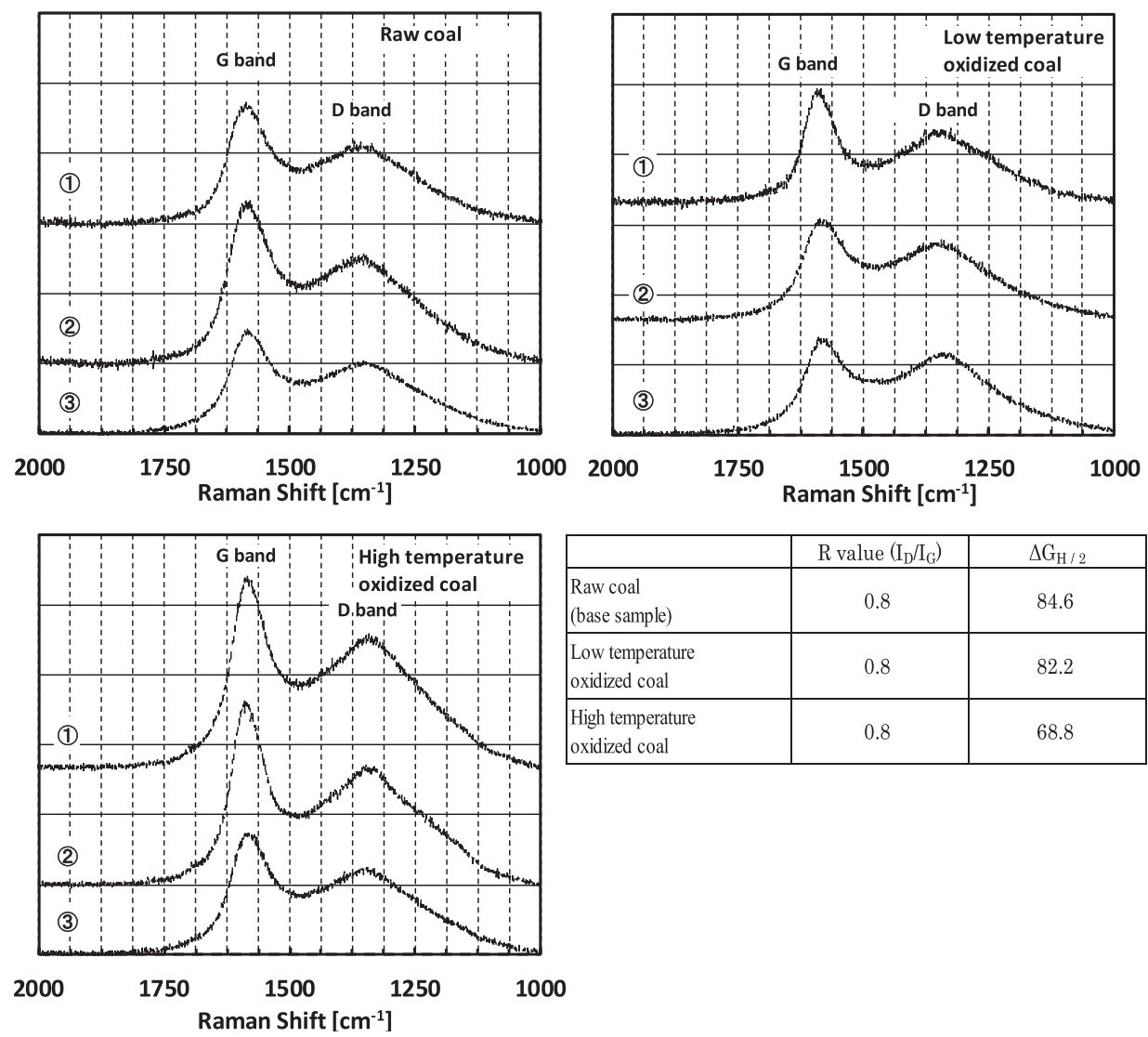

\begin{tabular}{|l|c|c|}
\hline & $R$ value $\left(\mathrm{I}_{\mathrm{D}} / \mathrm{I}_{\mathrm{G}}\right)$ & $\Delta \mathrm{G}_{\mathrm{H} / 2}$ \\
\hline $\begin{array}{l}\text { Raw coal } \\
\text { (base sample) }\end{array}$ & 0.8 & 84.6 \\
\hline $\begin{array}{l}\text { Low temperature } \\
\text { oxidized coal }\end{array}$ & 0.8 & 82.2 \\
\hline $\begin{array}{l}\text { High temperature } \\
\text { oxidized coal }\end{array}$ & 0.8 & 68.8 \\
\hline
\end{tabular}

Fig. 3. Raman spectra of coal samples.

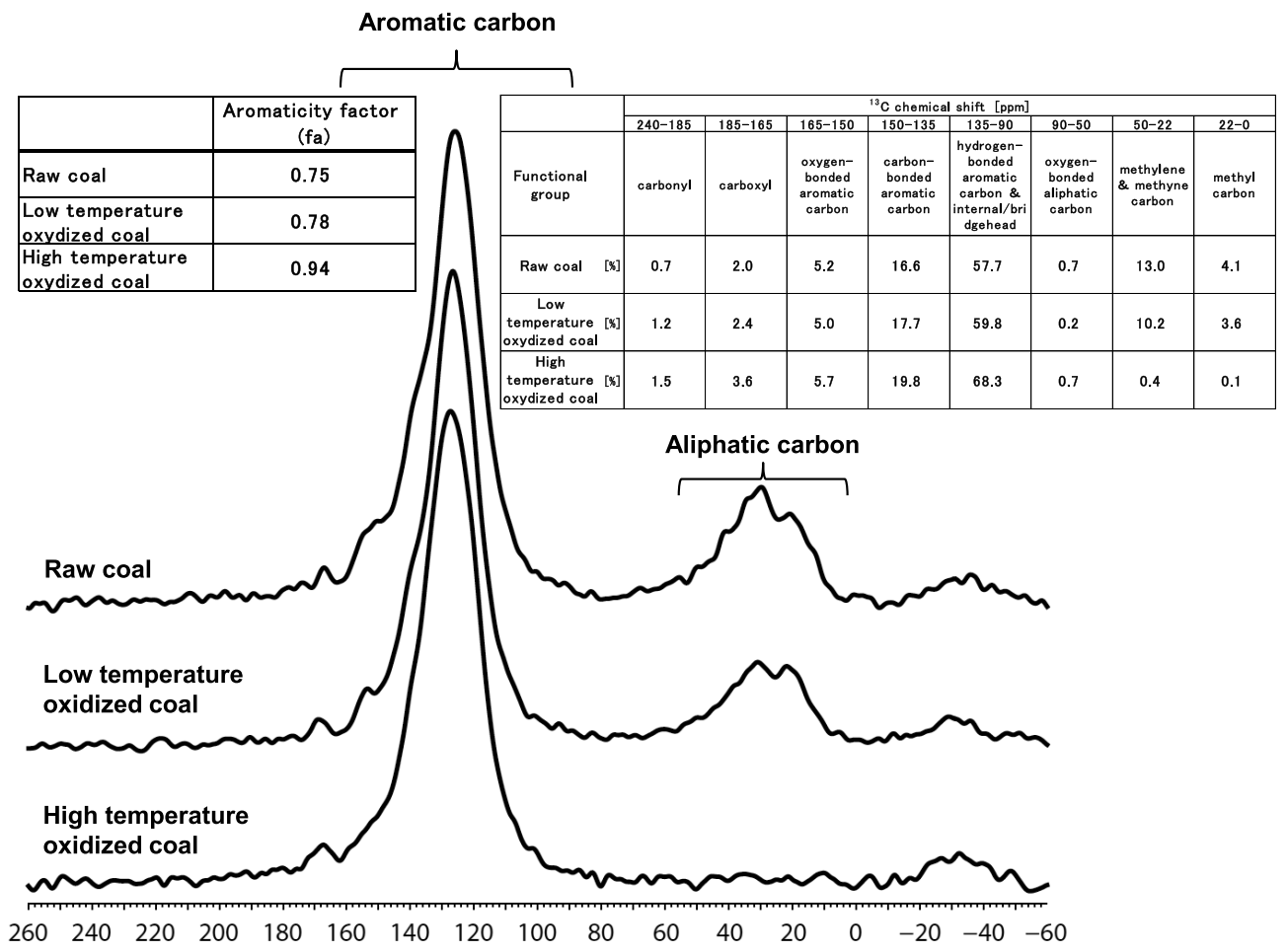

Fig. 4. Solid-state ${ }^{13} \mathrm{C}$ NMR spectra of coal samples.

or higher locally in its packed bed.

The above-mentioned tendency observed in the lowtemperature oxidation sample clearly appears in the hightemperature oxidation sample; the peak intensities brought about by aliphatic carbon decreased substantially. The peak intensity in the range of 0 to $22 \mathrm{ppm}$ corresponding to methyl groups decreased by approximately $4.0 \%$, and the peak intensities in the range of 22 to $50 \mathrm{ppm}$ corresponding to methylene and methine groups decreased by approximately $13 \%$. The results of the elemental analysis listed in Table 1. also show that the $\mathrm{H} / \mathrm{C}$ ratio of the high-temperature oxidation sample rapidly declined. Accordingly, the thermal 
decomposition reaction of aliphatic carbon is thought to have progressed. We confirmed that the aromatic carbon ratio $(\mathrm{fa})^{44)}$ increased from approximately 0.75 to 0.94 with the progress of this thermal decomposition reaction. In the hightemperature oxidation sample, we observed the reduction in the peak intensity with a peak top near 155 ppm brought about by aromatic carbon directly bonded to oxygen.

\subsection{Results of Infrared Spectroscopy (IR) Measure- ment}

The following describes the results of FTIR measurement of the changes in functional groups in coal due to oxidation. ${ }^{45)}$ Figure 5 shows the IR spectrum of each sample. While the samples were prepared using $\mathrm{KBr}$, it is known that $\mathrm{KBr}$ absorbs moisture that affects the $\mathrm{O}-\mathrm{H}$ stretching vibration near $3400 \mathrm{~cm}^{-1}$. ${ }^{46}$ ) To eliminate the effect of this moisture absorption, we assumed the portion equivalent to the spectrum obtained by IR measurement on $\mathrm{KBr}$ alone to be equivalent to the spectrum component affected by moisture absorption by $\mathrm{KBr}$, and removed this portion from the IR spectral intensity of each sample. This removal makes it possible to analyze the peak near $1640 \mathrm{~cm}^{-1}$ brought about by the $\mathrm{O}-\mathrm{H}$ deformation vibration.

In the spectrum of the low-temperature oxidation sample, the peak intensity near $3400 \mathrm{~cm}^{-1}$ brought about by the $\mathrm{O}-\mathrm{H}$ stretching vibration slightly increased, compared with that of the blended coal. Since the spectrum component affected by KBr's moisture absorption was removed as described above, it can be concluded that this change detected by IR corresponds to the production of functional groups in lowtemperature oxidation. For the low-temperature oxidation sample, the peak intensity in the range of 3600 to 3800 $\mathrm{cm}^{-1}$ brought about by kaolin decreased slightly. It has been reported that the $\mathrm{O}-\mathrm{H}$ peak intensity brought about by kaolin starts gradually decreasing at approximately $150^{\circ} \mathrm{C}^{41)} \mathrm{We}$ think that this result was due to a local temperature rise in the packed bed of the sample as described in the measurement results for solid ${ }^{13} \mathrm{C} \mathrm{NMR}$. The peak intensity near $1600 \mathrm{~cm}^{-1}$ brought about by aromatic carbon is equivalent to that of the blended coal; in contrast, the $\mathrm{C}-\mathrm{H}$ peak intensity near $1440 \mathrm{~cm}^{-1}$ brought about by aliphatic carbon decreased slightly for the low-temperature oxidation sample compared with that for the blended coal. This fact suggests that aliphatic side chains underwent thermal decomposition due to the low-temperature oxidation process.

Compared with the blended coal, the high-temperature oxidation sample exhibited decreases in the following peak intensities in the FTIR spectrum: $\mathrm{C}-\mathrm{H}$ stretching vibration brought about by aliphatic carbon $\left(2923 \mathrm{~cm}^{-1}\right), \mathrm{C}-\mathrm{H}$ deformation vibration brought about by aliphatic carbon (1 $\left.436 \mathrm{~cm}^{-1}\right), \mathrm{C}-\mathrm{H}$ stretching vibration brought about by aromatic carbon $\left(3040 \mathrm{~cm}^{-1}\right)$ and $\mathrm{C}=\mathrm{C}$ stretching vibration $\left(1587 \mathrm{~cm}^{-1}\right)$. The peak in the range of 3600 to 3800 $\mathrm{cm}^{-1}$ brought about by kaolin disappeared; this fact supports the occurrence of kaolin dehydration presumed on the basis of the XRD result (Fig. 2). The spectrum of the high-temperature oxidation sample is also characterized by the high background in the observed wave-number region. A possible factor causing this high background is that the carbon skeleton may have changed due to a thermal effect.

Using FTIR analysis, we revealed that in the lowtemperature oxidation sample, production of $\mathrm{O}-\mathrm{H}$ functional groups and a decrease in aliphatic side chains occurred. In the high-temperature oxidation sample, by contrast, not only did aliphatic carbon decrease, but also thermal decomposition of aromatic hydrocarbons and the dehydration of

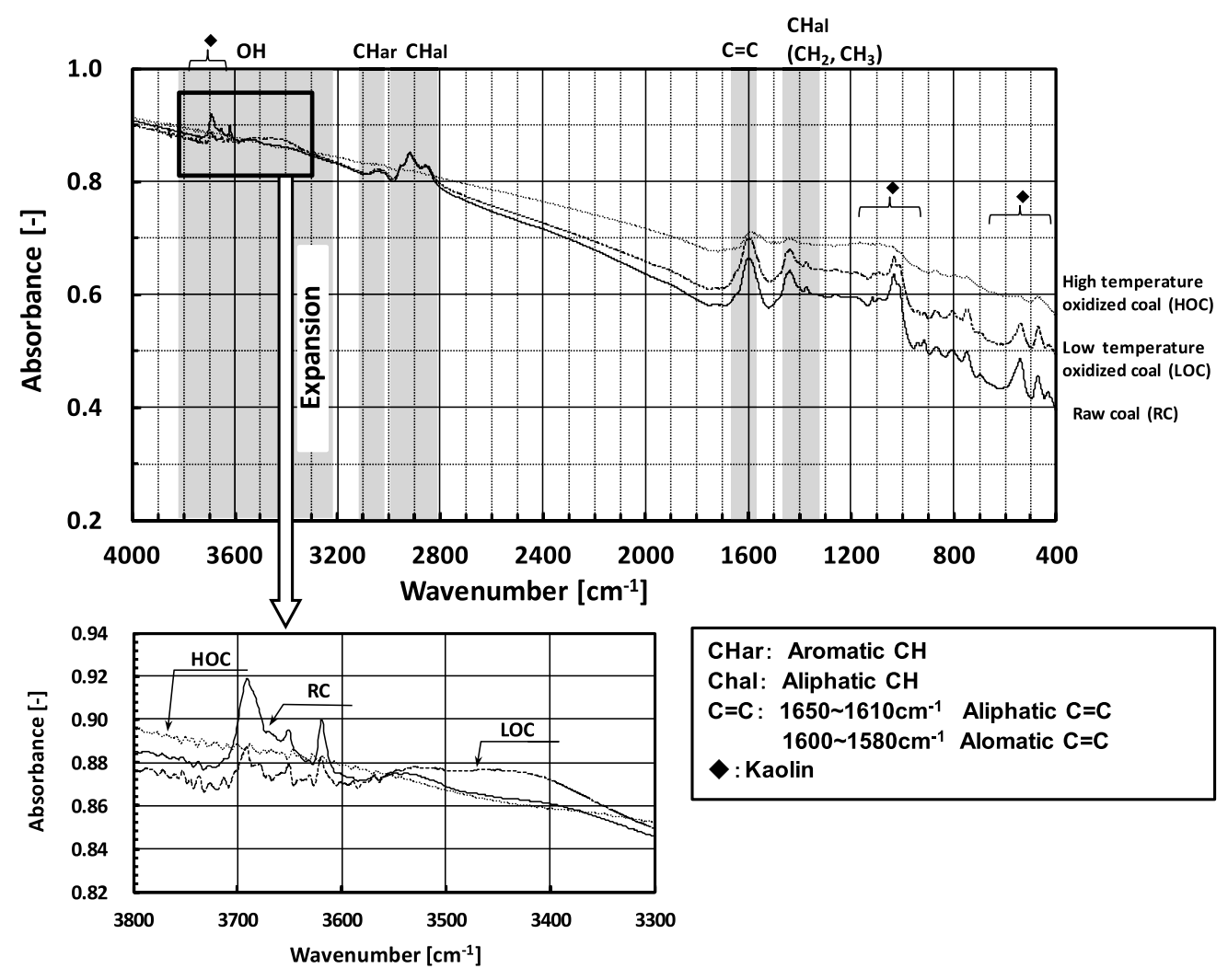

Fig. 5. FT- IR spectra of coal samples. 
inorganic matter contained in coal occurred. These results are not inconsistent with the measurement results for solid ${ }^{13} \mathrm{C}$ NMR.

\subsection{Measurement Results of Solid ${ }^{1} \mathrm{H}$ NMR}

To analyze changes in the low-temperature oxidation sample in more detail, we performed solid ${ }^{1} \mathrm{H}$ NMR spectrum measurement under the condition of high-speed spinning. ${ }^{47-49)}$ Figure 6 shows the results of comparing the chemical structures brought about by hydrogen atoms. The solid ${ }^{1} \mathrm{H}$ NMR spectra of the blended coal and the lowtemperature oxidation sample both exhibited peaks near 7 ppm and 2 ppm brought about by aromatic hydrogen and aliphatic hydrogen, respectively. In this measurement, we applied high-speed spinning to reduce the effect of broadening brought about by the dipole-dipole interaction between ${ }^{1} \mathrm{H}$ nuclei, and thereby quantitatively analyzed the peak intensities brought about by aromatic hydrogen and aliphatic hydrogen. The comparison of each peak intensity revealed that the amount of aliphatic hydrogen in the low-temperature oxidation sample decreased by approximately $15 \%$ compared with that in the blended coal. This value is larger than the decrease in the amount of aliphatic carbon detected by solid ${ }^{13} \mathrm{C}$ NMR. The reason may be that the decrease in the peak brought about by aliphatic hydrogen includes the reduction in the hydroxyl groups brought about by kaolin.

In low-temperature oxidation, a phenomenon in which the peak intensity brought about by aliphatic carbon decreased was thus detected using solid ${ }^{13} \mathrm{C} \mathrm{NMR}$. In addition, the production of $\mathrm{O}-\mathrm{H}-$ containing functional groups and the decrease in aliphatic side chains were detected with IR. From these results, we think the difference detected using solid ${ }^{1} \mathrm{H}$ NMR was a fine chemical-structure change due to low-temperature oxidation.

\subsection{Discussion}

Figure 7 shows changes in temperature inside the packed coal bed in the pail test, starting at a temperature of $80^{\circ} \mathrm{C}$, as well as changes in gas concentrations $\left(\mathrm{O}_{2}, \mathrm{CO}\right.$, and $\mathrm{CO}_{2}$ ) during the test. Gas analysis was performed with a PG-330 portable gas analyzer (Horiba, Ltd.). As this figure

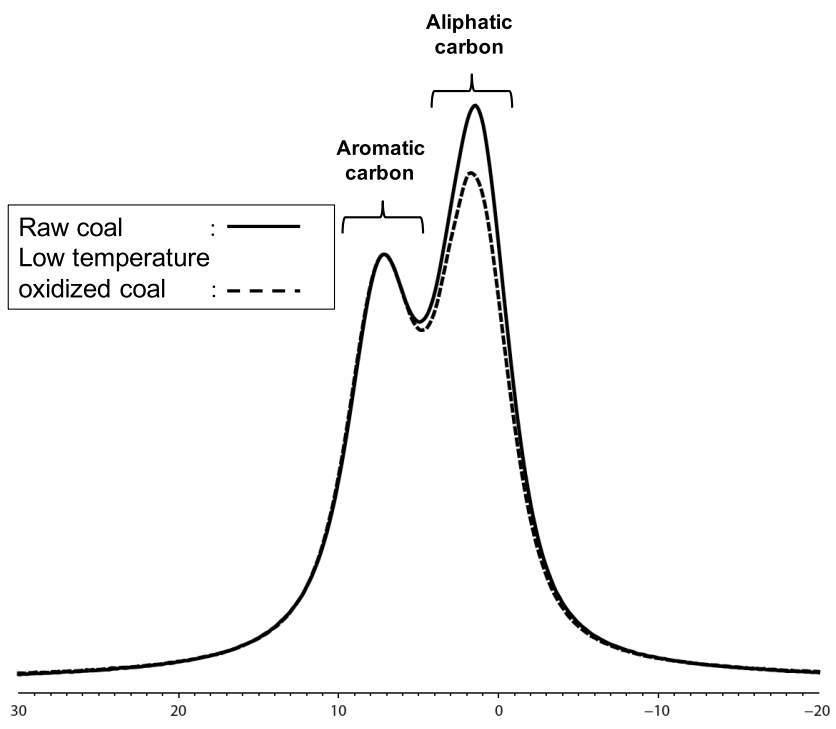

Fig. 6. Solid-state ${ }^{1} \mathrm{H}$ NMR spectra of coal samples. indicates, the $\mathrm{O}_{2}$ concentration started slowly decreasing approximately 0.5 days after the test began, whereas the $\mathrm{CO}_{2}$ concentration started slowly increasing approximately 1 day after the test started. Since the portable gas analyzer used is sufficiently accurate $\left( \pm 125 \mathrm{ppm}\right.$ for $\mathrm{O}_{2}, \pm 50 \mathrm{ppm}$ for $\mathrm{CO}$, and $\pm 100 \mathrm{ppm}$ for $\mathrm{CO}_{2}$ ), those changes can be regarded as significant ones. It is said that coal in a lowtemperature oxidation process generally adsorbs $\mathrm{O}_{2}$ first and then generates $\mathrm{CO}_{2}{ }^{50)}$ We think that a similar oxidation process accompanied by $\mathrm{O}_{2}$ adsorption and $\mathrm{CO}_{2}$ generation also occurred in the blended coal sample of this test.

With the aid of various types of analytical instruments as described above, we analyzed blended coal for coke production and the structural changes that occurred in the samples that were prepared by oxidizing the blended coal under a low-temperature condition (approximately $80^{\circ} \mathrm{C}$ ) or a high-temperature condition $\left(300^{\circ} \mathrm{C}\right.$ or higher). In the lowtemperature oxidation sample prepared at approximately $80^{\circ} \mathrm{C}$, neither XRD nor Raman spectroscopy revealed any clear structural changes. However, IR, solid ${ }^{13} \mathrm{C} \mathrm{NMR}$, and solid ${ }^{1} \mathrm{H}$ NMR did show a structural change due to a slight decrease in aliphatic functional groups and a decrease in the $\mathrm{O}-\mathrm{H}$ peak intensity brought about by kaolin. After thoroughly considering these results and those of the abovementioned gas analysis, we think that a local temperature rise to a level higher than the atmospheric temperature occurred in the sample in a packed-bed state and led to this phenomenon.

Existing reports have analyzed changes in functional groups in coal that has been sufficiently oxidized in a high-temperature oxidation test at $100^{\circ} \mathrm{C}$ or higher or in a long-term oxidation test for several days. In this study, we performed a low-temperature, short-term oxidation test and demonstrated that the decrease in aliphatic side chains and the production of hydroxyl groups occur in the initial oxidation process. These results were obtained not by using only one analysis method but by combining various different ones. Particularly, an analysis method based on an advanced approach that applies the nuclear magnetic resonance method allowed us to detect fine structural changes. It is generally thought that the low-temperature oxidation process in coal progresses from coal particle surfaces. ${ }^{19)}$ In this study, the chemical-structure changes accompanying low-temperature oxidation were small; we think the reason

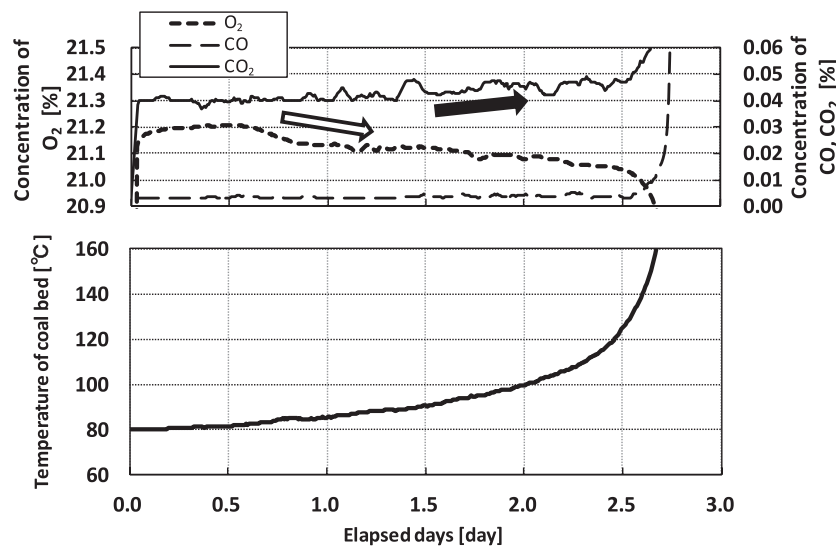

Fig. 7. Trend in temperature of coal bed and concentration of gases. 
is that only small amounts of functional groups structurally changed under oxidation because the oxidation rate at $80^{\circ} \mathrm{C}$ was small, or that the blended coal originally did not contain large amounts of functional groups that can be easily oxidized.

\section{Conclusions}

We oxidized blended coal for coke production in a layered state and analyzed its structural changes by performing various types of instrumental analyses (XRD, laser Raman spectroscopy, FTIR, and solid NMR) to trace the initial process of self-oxidation. Our findings are as follows.

We revealed that in a low-temperature oxidation process where coal in a packed state was exposed to air at $80^{\circ} \mathrm{C}$ for 24 hours, the carbon skeleton structure of coal does not change, but that a decrease in aliphatic side chains and the production of hydroxyl groups occur. We also found that a sample that underwent a high-temperature oxidation process with oxidation hysteresis at $300^{\circ} \mathrm{C}$ or higher exhibits substantial changes in the chemical structure of coal, such as a reduction in the volatile content, a decrease in the peaks brought about by aliphatic carbon and aromatic carbon, and change in the crystallinity of carbon. In this study, we observed only very small changes in molecular structures due to the low-temperature process. However, the changes clearly suggest that the process advances along a course different to that of the high-temperature oxidation process. We think that the self-heating of coal is promoted by the synergistic action of the oxidation process and the heat generated by the oxidation process; the heat generated by the oxidation process further accelerates the oxidation process. Our findings in this study are that chemical structures change under relatively low heat generation during the initial stage of the oxidation process. We expect that the findings will substantially contribute to the understanding of self-heating and the reduction of self-heating. In this study, however, we have not reached a detailed understanding of the initial oxidation process, such as identifying reaction sites. We believe it is necessary to enhance the sensitivity of analytical instruments and to develop new approaches for elucidating the mechanism behind the oxidation process in blended coal in this area.

\section{Acknowledgements}

We would like to thank Dr. Isao Mochida, a professor emeritus of Kyushu University, for his advice regarding the discussions on the experimental results of this study.

\section{REFERENCES}

1) The Japan Iron and Steel Federation: Japanese Steel Industry 2014, JISF, Tokyo, (2014).

2) Y. Kubota, S. Nomura, T. Arima and K. Kato: Tetsu-to-Hagané, 92 (2006), 833 (in Japanese).

3) Y. Kubota, K. Ikeda, T. Arima, S. Nomura and Y. Aihara: Tetsu-toHagané, 99 (2013), 175 (in Japanese).

4) S. Nomura, T. Arima and K. Kato: Fuel, 83 (2004), 1771.

5) S. Wakuri, M. Ohno, K. Hosokawa, K. Nakagawa, Y. Takanohashi, T. Ohnishi, K. Kushioka and Y. Konno: 45th Ironmaking Conf. Proc.,
Iron and Steel Society, Warrendale, PA, (1986), 303.

6) K. Nishioka: Tetsu-to-Hagané, 82 (1996), 353 (in Japanese).

7) Y. Nakashima, S. Mochizuki, S. Ito, K. Nakagawa, K. Nishimoto and K. Kobayashi: Proc. 2nd Int. Cokemaking Cong., Institute of Materials, London, (1992), 518.

8) S. Tanaka, K. Okanishi, A. Kikuchi and Y. Yamamura: 56th Ironmaking Conf. Proc., Iron and Steel Society, Warrendale, PA, (1997), 139.

9) K. Nishioka, H. Oshima, I. Sugiyama and H. Fujikawa: Tetsu-toHagané, 90 (2004), 614 (in Japanese).

10) K. Miura: J. Jpn. Inst. Energy, 94 (2015), 1169.

11) H. Miyakoshi, S. Isobe and K. Otsuka: J. Min. Metall. Inst. Jpn., 100 (1984), 643

12) J. M. Kuchta, V. R. Rowe and D. S. Burgess: Spontaneous Combustion Susceptibility of US Coals, RI 8474, US Bureau of Mines, Washington, D.C., (1980).

13) D. Cliff, D. Rowlands and J. Sleeman: Spontaneous Combustion in Australian Underground Coal Mines, Simtars, Redbank, Queensland, Australia, (1996).

14) V. N. Marinov: Fuel, 56 (1977), 158.

15) V. N. Marinov: Fuel, 56 (1977), 165

16) S. C. Banerjee and R. N. Chakravorty: J. Min. Met. Fuels, 15 (1967),

17) R. Kaji, Y. Hishinuma and Y. Nakamura: Fuel, 66 (1987), 154.

18) B. C. Young and P. Nordon: Fuel, 57 (1978), 574.

19) H. Ota and T. Takarada: Proc. Conf. Coal Sci., 36 (1999), 355

20) J. S. Gethner: Fuel, 64 (1985), 1443.

21) Y. Yurum and N. Altuntas: Fuel, 77 (1998), 1809

22) D. L. Perry and A. Grint: Fuel, 62 (1989), 1024.

23) J. A. MacPhee and B. N. Nandi: Fuel, 60 (1981), 169

24) H. Ota and T. Takarada: Proc. Conf. Coal Sci., Tokyo, 38 (2001), 87.

$25)$ K. Sato, A. Suzuki, T. Takarada, S. Yamamoto, M. Hamaguchi and T. Inoue: Proc. 21st Conf. of Japan Institute of Energy, The Japan Institute of Energy, Tokyo, (2011), 20.

26) A. H. Clemens, T. W. Matheson and D. E. Rogers: Fuel, 70 (1991), 215.

27) G. Wang and A. Zhou: Int. J. Min. Sci. Technol., 22 (2012), 517.

28) M. Uchida, T. Tsutsumi, H. Suzuki, K. Uebo, Y. Suzuki, S. Nomura, K. Saito, Y. Doko, M. Otaka, M. Kimoto and H. Makino: J. Soc. Powder Technol., 53 (2016), 286.

$29)$ B. B. Beamish, A. G. Lau, A. L. Moodile and T. A. Vallance: J. Loss Prev. Process Ind., 15 (2002), 385.

30) B. B. Beamish and I. Jabouri: Proc. Coal 2005 Coal Operator's Conf., Australasian Institute of Mining and Metallurgy, Carlton, Victoria, Australia, (2005), 187

31) A. Sadezky, H. Muckenhuber, H. Grothe, R. Niessner and U. Poschl: Carbon, 43 (2005), 1731.

32) D. G. Cory and W. M. Ritchey: J. Magn. Reson., 80 (1988), 128.

$33)$ N. Yoshizawa: J. Jpn. Inst. Energy, 88 (2009), 96.

34) H. Orikasa, H. Nishihara, Q. H. Yang, K. Matsuoka, T. Kyotani, A. Sharma, K. Matsui, H. Fujimoto, K. Fukada and K. Kato: Tetsu-toHagané, 92 (2006), 137 (in Japanese).

35) T. Tomita, K. Tanabe and K. Yamamoto: J. Jpn. Soc. Civ. Eng., 445 (1992), 55 (in Japanese).

36) I. Noda and M. Inagaki: Japan Society for the Promotion of Science 117 Committee Materials, 117-71-A-1, Japan Society for the Promotion of Science, Tokyo, (1963), 25.

37) M. Inagaki: Japan Society for the Promotion of Science 117 Committee Materials, 117-121-C-5, Japan Society for the Promotion of Science, Tokyo, (1972), 139.

38) M. Inagaki: Tanso, 1963 (1963), No. 36, 28 (in Japanese).

39) P. Lespade, R. Al-Jishi and M. S. Dresselhaus: Carbon, 20 (1982), 427.

40) F. Tuinstra and J. L. Koenig: J. Chem. Phys., 35 (1970), 1126.

41) M. Nakamizo, H. Honda and M. Inagaki: Carbon, 16 (1978), 281.

42) K. Saito and K. Kanehashi: J. Jpn. Inst. Energy, 90 (2011), 474.

43) Y. Fujioka, M. Nishifuji, K. Saito and K. Kato: Tetsu-to-Hagané, 88 (2002), 507 (in Japanese).

44) J. K. Brownand and W. R. Ladner: Fuel, 39 (1960), 79.

45) H. Fujitsu and I. Mochida: J. Fuel Soc. Jpn., 64 (1985), 911 (in Japanese).

46) C. A. Rhoads, J. T. Secftle, M. M. Coleman, A. Davis and P. C. Painter: Fuel, 62 (1983), 1387.

47) M. Sakawa: Tetsu-to-Hagané, 82 (1996), 347 (in Japanese).

48) K. Saito, M. Hatakeyama, M. Matsuura, K. Kato and I. Komaki: Tetsu-to-Hagané, 85 (1999), 195 (in Japanese).

49) A. Wickramasinghe, S. Wang, I. Matsuda, Y. Nishiyama, T. Nemoto, Y. Endo and Y. Ishii: Solid State Nucl. Magn. Reson., 72 (2015), 9.

50) D. W. van Krevellen: Coal, Elsevier, Amsterdam, (1993), 627. 